\title{
Effect of boric acid sintering aid on densification of barium ferrite
}

\author{
S S VIDYAWATHI*, R AMARESH and L N SATAPATHY ${ }^{\dagger}$ \\ Department of Ceramic Engineering, P.D.A. College of Engineering, Gulbarga 585 102, India \\ ${ }^{\dagger}$ Ceramic Technological Institute, Ceramic Business Unit, BHEL, Bangalore 560 012, India
}

\begin{abstract}
Boric acid has been added in 0.1-0.6\% range for studying the densification characteristics of solid state sintered barium hexaferrite. Sintering studies have been carried out at three different temperatures. Physical properties like density and porosity have been studied for all compositions. The phase identification and microstructural investigation on the fractured surface have been carried out to understand the effect of sintering aid on the densification characteristics.
\end{abstract}

Keywords. Barium ferrite; sintering aid; densification.

\section{Introduction}

The magnetic properties of the ferrites are known to depend largely on the microstructure such as grain size and grain size distribution. To obtain high magneto crystalline anisotropy, the sintered barium hexaferrite should have single phase with submicron particle sizes.

Various methods have been used in the literature to prepare barium ferrite. The material has been prepared by coprecipitation (Roos 1980), organic resin method (Licci and Besagni 1984), aerosol synthesis (Cabanas et al 1994), microemulsion mediated process (Pillai et al 1992) and sol-gel synthesis (Zhong et al 1997). However, the solid state sintering method is an easy, cost-effective process for fabricating barium ferrite powders.

Boric acid has been used as an effective additive for ceramic materials like $\mathrm{BN}, \mathrm{B}_{4} \mathrm{C}, \mathrm{SiC}$. It is a low-cost and relatively non-hazardous material and thus finds promising as an additive in many ceramic processing. Effort has been made here to utilize this material as an additive in ferrite synthesis by the conventional solid state sintering route of producing barium ferrite.

\section{Experimental}

The raw materials used in this work were barium carbonate $\left(\mathrm{BaCO}_{3}\right)$ and ferric oxide $\left(\mathrm{Fe}_{2} \mathrm{O}_{3}\right)$. The sintering aid boric acid $\left(\mathrm{H}_{3} \mathrm{BO}_{3}\right)$ was varied as $0,0 \cdot 1,0 \cdot 4$ and $0.6 \mathrm{wt} \%$ in the raw material mixture. The typical impurities in the raw materials were: $\mathrm{BaCO}_{3}$ (purity 99.0\%, Pb: 0.002, Cl: 0.05 , Fe: 0.005 , and S: 0.05 , LOI: 0.956) and $\mathrm{Fe}_{2} \mathrm{O}_{3}$ (purity $99 \%$, other impurities $0.36 \%$ with LOI of $0.64 \%$ ).

The raw materials were weighed in calculated amount and red milled in a pot mill with alumina balls for $12 \mathrm{~h}$ in

\footnotetext{
*Author for correspondence
}

alcohol. The sintering aid was added as powder into the mixture and milled for homogenous mixing. The milled mixture was dried and calcined at a temperature of $1523 \mathrm{~K}$ for $2 \mathrm{~h}$. The calcined powder was pelletized at $30 \mathrm{MPa}$ pressure using a metal die and hydraulic press and sintered in a muffle furnace at three different temperatures of 1473,1573 and $1673 \mathrm{~K}$ for $2 \mathrm{~h}$ duration. The green density was measured by dimensional method prior to sintering by using vernier and electronic balance. The sintered samples were measured for density and porosity by boiling water method. The fracture surface was observed in scanning electron microscope. The phase identification study was carried out by X-ray diffractometer.

\section{Results and discussion}

The physical properties of different compositions are given in table 1.

Figure 1 summarizes the variation of fired density with amount of sintering aid. Similarly, figure 2 summarizes the variation of porosity after firing as a function of amount of sintering aid. It was observed that the density improved by increasing the temperature from $1473 \mathrm{~K}$ to $1573 \mathrm{~K}$. However, the density was lower at a higher temperature of $1673 \mathrm{~K}$. The lowering in density was prominent in composition with $0.6 \%$ sintering aid. In all cases, though the theoretical density $(5.26 \mathrm{~g} / \mathrm{cc})$ could not be achieved but the composition with $0.6 \%$ sintering aid was found to be promising to achieve the theoretical density. The densification characteristics were also reflected in the amount of porosity. The porosity was very high (figure 2 ) for the samples sintered at $1473 \mathrm{~K}$ compared to other two temperatures. It was also observed that the amount of porosity reduced with increase in sintering aid at $1473 \mathrm{~K}$. The lower densities at higher temperature also reflected as higher porosity in such conditions. This analysis indicated 
Table 1. Densification characteristics of barium ferrite with $\mathrm{H}_{3} \mathrm{BO}_{3}$ as sintering aid.

\begin{tabular}{|c|c|c|c|c|c|c|c|}
\hline \multirow[b]{2}{*}{$\begin{array}{l}\mathrm{H}_{3} \mathrm{BO}_{3} \\
(\%)\end{array}$} & \multirow[b]{2}{*}{$\begin{array}{l}\text { G.D. } \\
\text { (g/cc) }\end{array}$} & \multicolumn{2}{|c|}{$T=1473 \mathrm{~K}$} & \multicolumn{2}{|c|}{$T=1573 \mathrm{~K}$} & \multicolumn{2}{|c|}{$T=1673 \mathrm{~K}$} \\
\hline & & $\begin{array}{l}\text { B.D. } \\
\text { (g/cc) }\end{array}$ & $\begin{array}{l}\text { A.P. } \\
(\%)\end{array}$ & $\begin{array}{l}\text { B.D. } \\
\text { (g/cc) }\end{array}$ & $\begin{array}{l}\text { A.P. } \\
(\%)\end{array}$ & $\begin{array}{l}\text { B.D. } \\
\text { (g/cc) }\end{array}$ & $\begin{array}{l}\text { A.P. } \\
(\%)\end{array}$ \\
\hline $0 \cdot 0$ & $3 \cdot 41$ & $4 \cdot 3$ & $12 \cdot 1$ & $4 \cdot 4$ & 0.03 & $4 \cdot 528$ & 1.5 \\
\hline $0 \cdot 1$ & $3 \cdot 36$ & $4 \cdot 1$ & 17.9 & $4 \cdot 6$ & 0.06 & $4 \cdot 5$ & 1.5 \\
\hline $0 \cdot 4$ & $3 \cdot 46$ & $4 \cdot 3$ & $13 \cdot 9$ & $4 \cdot 5$ & 0.03 & $4 \cdot 4$ & $1 \cdot 2$ \\
\hline 0.6 & $3 \cdot 50$ & $4 \cdot 5$ & $6 \cdot 2$ & $5 \cdot 16$ & 0.07 & $4 \cdot 5$ & $0 \cdot 0$ \\
\hline
\end{tabular}

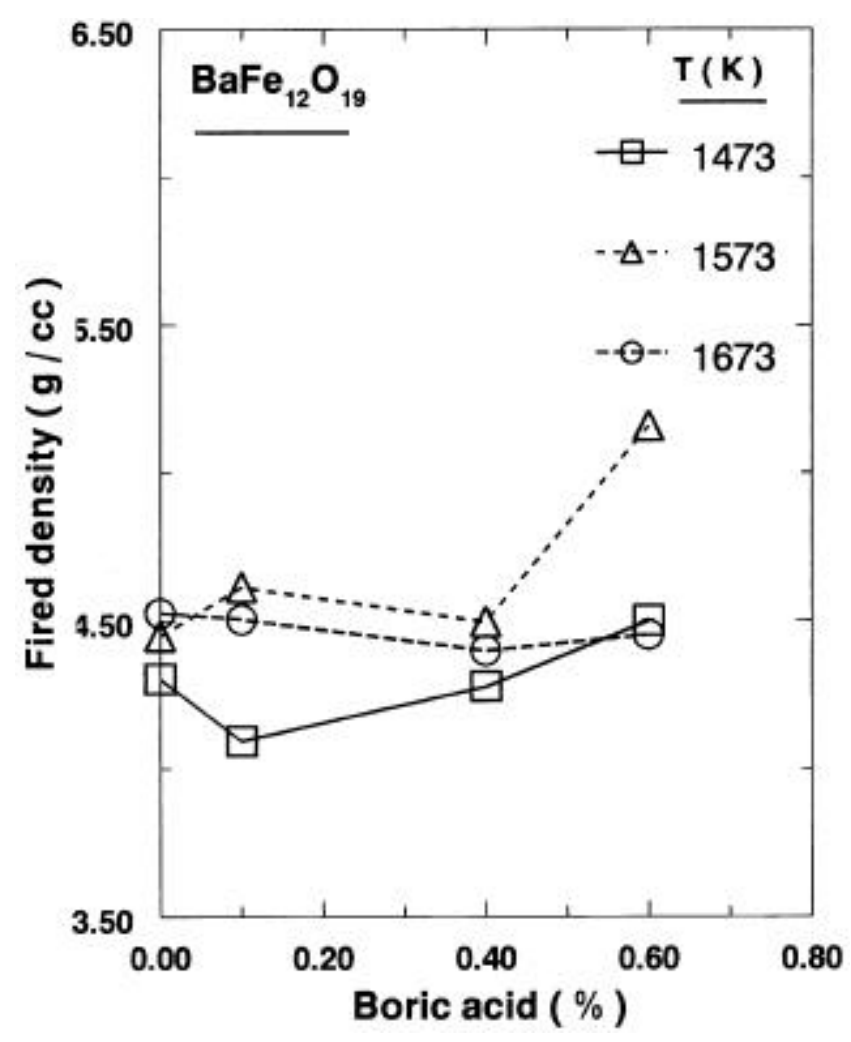

Figure 1. Variation of bulk density of barium ferrite with amount of sintering aid. The samples were sintered at different temperatures.

that the effect of sintering aid is maximum at 1473 and $1573 \mathrm{~K}$ without having much effect in high temperature conditions. The amount of sintering aid plays an important role in densification as observed in figure 1 for the samples sintered at $1773 \mathrm{~K}$. The origin of lower density at high temperature could be due to grain growth leading to defects in the body. Keeping this in view, it was planned to characterize the microstructure of this material in the low temperature processing condition.

The X-ray diffraction pattern of $0.6 \%$ sintering aid in barium ferrite which was sintered at $1473 \mathrm{~K} / 2 \mathrm{~h}$ (figure 3 ) indicated that the formation of barium ferrite from the reaction of raw materials is not complete. As a result of

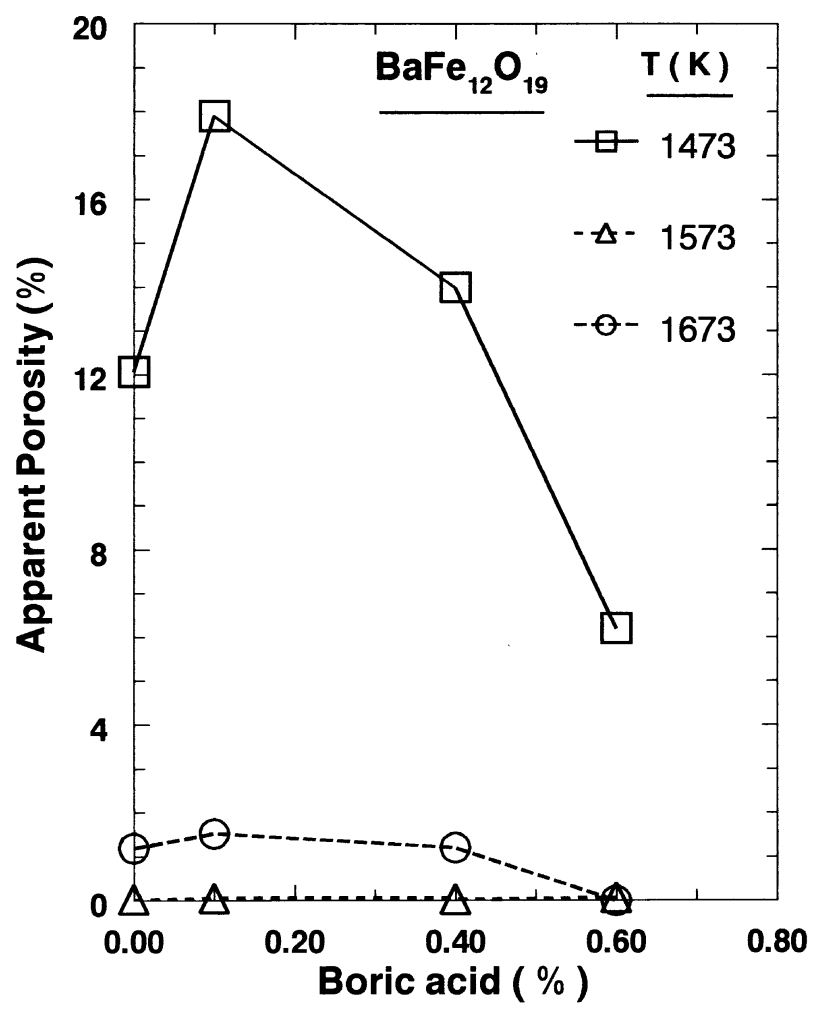

Figure 2. Variation of apparent porosity of barium ferrite with amount of sintering aid. The samples were sintered at different temperatures.

which, some unreacted iron oxide phases were found in the pattern. The reaction of ferrite formation given below

$$
\begin{aligned}
& \mathrm{Fe}_{2} \mathrm{O}_{3}+\mathrm{BaCO}_{3} \rightarrow \mathrm{BaFe}_{2} \mathrm{O}_{4}+\mathrm{CO}_{2}, \\
& \mathrm{BaFe}_{2} \mathrm{O}_{4}+5 \mathrm{Fe}_{2} \mathrm{O}_{3} \rightarrow \mathrm{BaFe}_{12} \mathrm{O}_{19},
\end{aligned}
$$

probably needs high sintering temperature or longer duration at that temperature. This was also confirmed from the high temperature sintering experiments where the densification was better compared to that at lower temperature.

The scanning electron micrographs of barium ferrite fracture surface with $0 \%$ and $0.6 \%$ sintering aids are given 


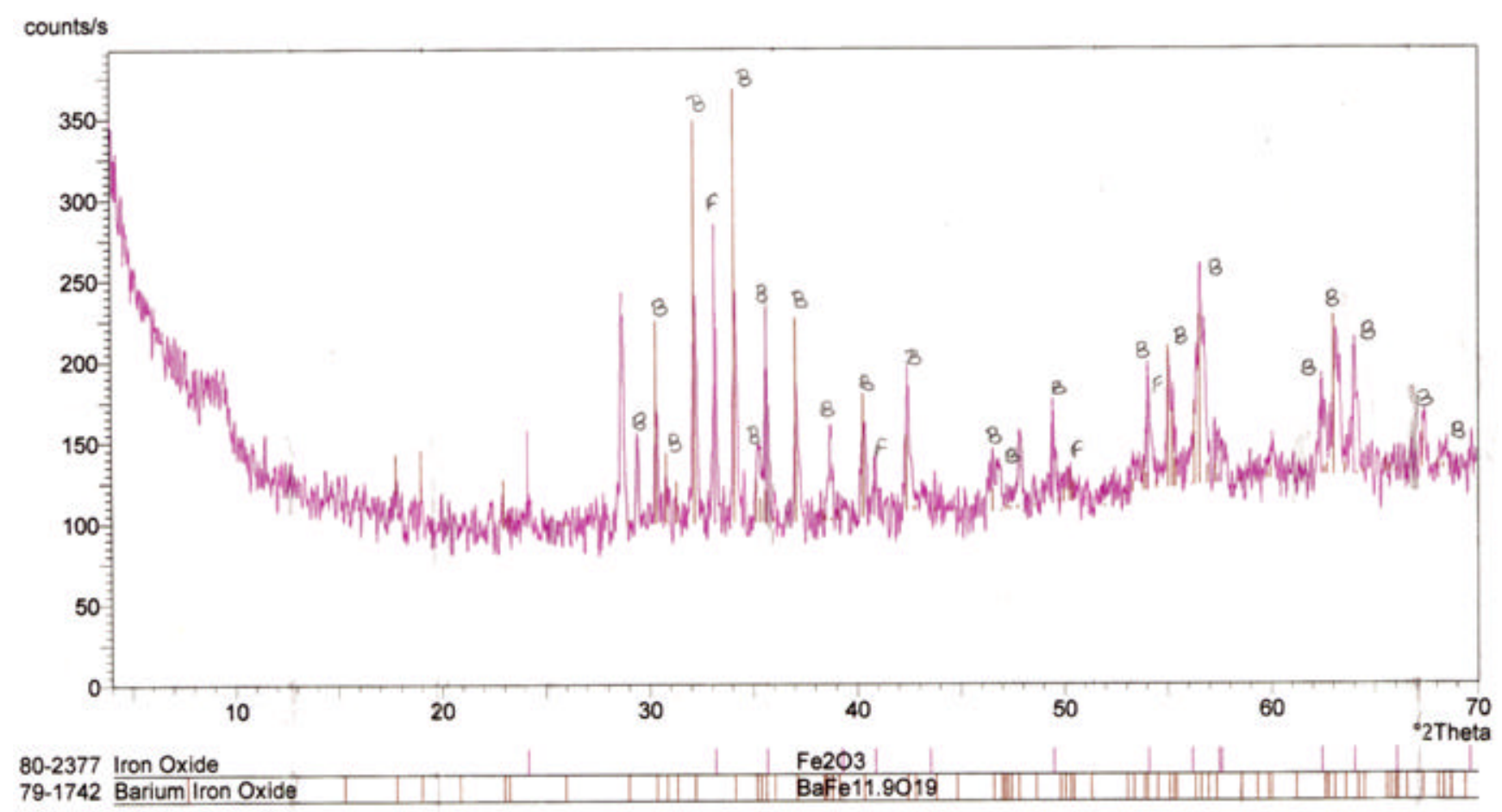

Figure 3. X-ray diffraction pattern of barium ferrite which was sintered at $1473 \mathrm{~K} / 2 \mathrm{~h}$. The pattern revealed both barium ferrite (B) and unreacted $\mathrm{Fe}_{2} \mathrm{O}_{3}(\mathrm{~F})$ phase.
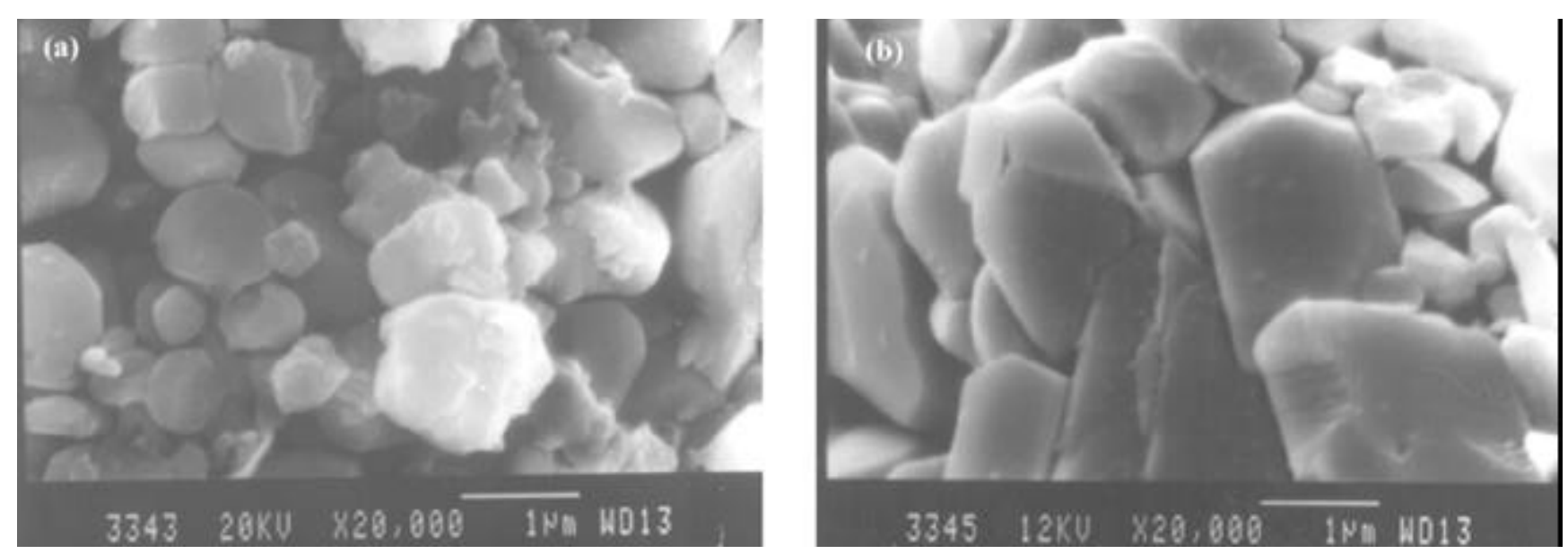

Figure 4. Scanning electron micrographs of barium ferrite (a) without any additive and (b) with $0 \cdot 6 \%$ boric acid as sintering aid. The material was sintered at $1473 \mathrm{~K} / 2 \mathrm{~h}$.

in figures $4 \mathrm{a}$ and $\mathrm{b}$. It was observed that the grain size was quite fine in both cases. However, the grain shapes were different. The material with sintering aid was found to possess oriented grains compared to that of random grains in the material without sintering aid. These materials were sintered at $1473 \mathrm{~K} / 2 \mathrm{~h}$. Though there is no relationship available on the orientation of grains with sintering aid, but the experimental results are beneficial from the application point of view. Similar kind of platy structures as observed in figure 4 a has also been observed earlier by Zhong et al (1997); the powder was prepared by sol-gel method. However, observation of oriented grains in ferrite by solid state sintering method is rare in the literature. 


\section{Conclusions}

In this study, the effect of boric acid sintering aid has been studied on the densification of barium ferrite by solid state sintering method. It was observed that the sintering aid is effective at lower temperature compared to high temperature sintering. A small quantity $\sim 0.6 \%$ of low cost sintering aid is effective in densification of barium ferrite. The orientation of grains could be observed in micrograph of barium ferrite, which was added with sintering aid, and sintered at $1473 \mathrm{~K}$.

\section{References}

Cabanas M V, Gonzalez-Calbet J M and Vallet-Reggi M 1994 J. Mater. Res. 9712

Haneda K, Miyakawa C and Kojima H 1974 J. Am. Ceram. Soc. 57354

Licci F and Besagni T 1984 IEEE Trans. Magn. 201639

Pillai V, Kumar P and Shah D O 1992 J. Magn. Magn. Mater. 116 L299

Roos W 1980 J. Am. Ceram. Soc. 63601

Zhong W, Ding W, Jiang Y, Zhang J, Du Y and Yan Q 1997 J. Am. Ceram. Soc. 803258 